\title{
Regional-scale analysis of lake outburst hazards in the southwestern Pamir, Tajikistan, based on remote sensing and GIS
}

\author{
M. Mergili and J. F. Schneider \\ Institute of Applied Geology, BOKU University of Natural Resources and Life Sciences Vienna, Peter-Jordan-Straße 70, \\ 1190 Vienna, Austria
}

Received: 19 November 2010 - Revised: 29 March 2011 - Accepted: 5 April 2011 - Published: 18 May 2011

\begin{abstract}
This paper presents an analysis of the hazards emanating from the sudden drainage of alpine lakes in SouthWestern Tajik Pamir. In the last 40 yr, several new lakes have formed in the front of retreating glacier tongues, and existing lakes have grown. Other lakes are dammed by landslide deposits or older moraines. In 2002, sudden drainage of a glacial lake in the area triggered a catastrophic debris flow. Building on existing approaches, a rating scheme was devised allowing quick, regional-scale identification of potentially hazardous lakes and possible impact areas. This approach relies on GIS, remote sensing and empirical modelling, largely based on medium-resolution international datasets. Out of the 428 lakes mapped in the area, 6 were rated very hazardous and 34 hazardous. This classification was used for the selection of lakes requiring in-depth investigation. Selected cases are presented and discussed in order to understand the potentials and limitations of the approach used. Such an understanding is essential for the appropriate application of the methodology for risk mitigation purposes.
\end{abstract}

\section{Introduction}

Natural dams of different size and origin exist in mountain areas all over the world (Costa and Schuster, 1988). They often retain lakes which, in the case of a dam failure, may drain as powerful floods. If the failed dam is a glacier or a feature of a glacially shaped landscape, such events are called Glacial Lake Outburst Floods (GLOFs). Sudden drainage of glacial lakes has been reported from the Himalayas, the mountains of Central Asia, the North American mountains, the South American Andes, New Zealand and the Alps.

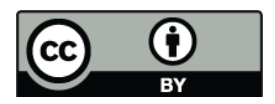

Correspondence to: M. Mergili

(martin.mergili@boku.ac.at) (e.g. Clarke, 1982; Hewitt, 1982; Haeberli, 1983; Watanabe and Rothacher, 1996; Richardson and Reynolds, 2000; Vilímek et al., 2005; Narama et al., 2010). Climate change, with its impact on the glacial extent, the hydrological cycle and the condition of ice-bearing dams, may condition the occurrence of GLOFs in manifold ways and on different time scales (Evans and Clague, 1994; IPCC, 2007; Dussaillant et al., 2009; Haeberli et al., 2010a).

But also other types of lakes - particularly such dammed by landslide deposits - may be subjected to sudden drainage (Costa and Schuster, 1991). Lake outburst floods (referred to as LOFs in the present paper, including both glacial and non-glacial lakes) often have a highly destructive potential. A large amount of water is released within a short time, with a high capacity to erode loose debris, potentially leading to a powerful flow with a long travel distance. Peak discharges are often some magnitudes higher than in the case of "normal" floods (Cenderella and Wohl, 2001).

LOFs can evolve in different ways, possible causes are:

1. landslides, rock/ice avalanches or calving glaciers that produce flood waves in a pro- or supraglacial lake which may overtop and possibly breach glacial, morainic or landslide dams (Tinti et al., 1999);

2. rising lake levels, leading to progressive incision and destabilization of a dam;

3. hydrostatic failure of ice dams or enhanced ground water flow (piping), which can cause sudden outflow of accumulated water (Iturrizaga, 2005a, b);

4. degradation of glacier dams or ice cores in morainic dams leading to loss of stability and to subsidence resulting in internal failure or progressive erosion if a certain threshold is reached.

Published by Copernicus Publications on behalf of the European Geosciences Union. 
Richardson and Reynolds (2000) and Haeberli et al. (2010a) provide overviews of the conditioning and triggering factors of lake outburst floods, dam failure mechanisms and process interactions, as well as case studies.

Even though lakes can be identified relatively easily with remote sensing tools and field work (e.g. Huggel et al., 2004b; Kääb et al., 2005; Quincey et al., 2007), the selection of potentially hazardous lakes, the prediction of outburst floods and modelling of the motion and reach of specific LOFs still remain a challenge (Kargel et al., 2010; Mergili et al., 2011). Changes in flow behaviour (e.g. from clear water flow to hyperconcentrated flow and debris flow or reverse) imply some difficulties when using computer models to predict LOF velocities and travel distances.

This paper presents a lake outburst susceptibility and hazard analysis for a selected area of the southwestern Pamir, focusing on the regional scale: GIS and Remote Sensing approaches are applied, allowing a quick identification of potentially hazardous lakes and possible impact areas over a large area. The results of such a study facilitate the selection of sites requiring more detailed studies and serve as a baseline for risk mitigation strategies in the region. It is attempted to push the methodology for this type of analysis forward, building on existing approaches (e.g. Reynolds, 2003; Huggel et al., 2004a).

\section{Study area}

The study presented covers the Gunt and Shakhdara valleys in southwestern Tajik Pamir (Fig. 1). It covers a total surface area of $8430 \mathrm{~km}^{2}$. The Gunt River originates in the highlands of the eastern Pamir and joins the Panj River near the town of Khorog (2075 m a.s.1.). The Shakhdara Valley is a southern tributary of the Gunt Valley with the confluence just upstream from Khorog. From north to south, the valleys are separated by the Rushan Range (culminating at $6068 \mathrm{~m}$ a.s.l.), the Shugnan Range $(5708 \mathrm{~m})$ and the Shakhdara Range $(6723 \mathrm{~m})$, all stretching in an east-west direction. The northsouth stretching Ishkashim Range (6095 m) follows directly northwest of the Shakhdara Range. In terms of geology, gneisses dominate the area, with remnants of a former sedimentary cover particularly in the northern portion. The area is seismically active with frequent earthquakes (e.g. Babaev and Mirzoev, 1976).

The area covers the districts of Shugnan (Gunt Valley) and Roshtkala (Shakhdara Valley) under the Gorno-Badakhshan Autonomous Oblast of the Republic of Tajikistan with the regional centre of Khorog. Except for Khorog, the population largely depends on agriculture and pastoralism. Industry, service, and tourism are poorly developed. The permanent settlements are concentrated close to the valley bottom and depend on irrigation with melt water. Transhumance to distant summer pastures in the upper valleys is common (Kassam, 2009).

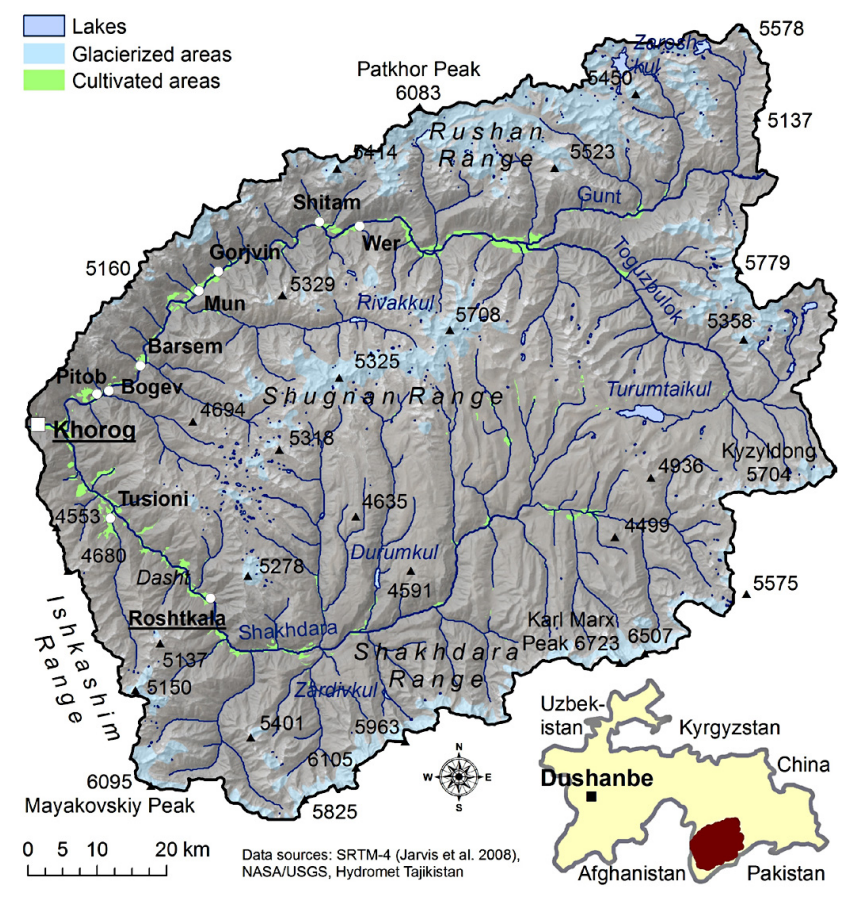

Fig. 1. The study area.

The climate is semi-arid to arid, with an annual mean precipitation of $288 \mathrm{~mm}$. Most of it occurs during winter and spring. The average annual air temperature is $9.2^{\circ} \mathrm{C}$ (Khorog; 1970-2008). High-altitude meteorological data is missing. The major mountain ranges are glacierized, but most of the glaciers are in a stage of retreat. Many glacier tongues are covered by debris, so that it is hard to delineate their extent from satellite imagery or superficial field surveys.

Whilst many glaciers in the northern Pamir have shown a variable behaviour during the previous decades or surge at certain intervals (e.g. Kotlyakov et al., 2008), the glaciers in the southwestern Pamir have been shrinking for several decades. Numerous lakes have formed in the front or on the top of retreating glacier tongues, and several more are retained by holocene landslide or moraine dams and in depressions within the glacially shaped terrain.

Altogether, 428 lakes were identified in the study area (including only those with a surface area $\geq 2500 \mathrm{~m}^{2}$ ). The majority of the lakes is found in the direct forefield of the recent glaciers and on the undulating highlands shaped by Pleistocenic glaciers. 90 per cent of all lakes are located between 4200-4900 m a.s.l. Some of the larger lakes, however, dammed by holocene landslides and/or terminal moraines from the Pleistocene, are located at lower elevation (e.g. Rivakkul, Durumkul, Zardivkul). No lakes at all were identified below $3341 \mathrm{~m}$ a.s.l. 


\section{The Dasht 2002 event}

On 7 August 2002, the village of Dasht (Shakhdara Valley) was hit by a GLOF. $10.5 \mathrm{~km}$ upstream in the headwaters of the valley, a lake with a surface of $37000 \mathrm{~m}^{2}$, located on the decaying tongue of a debris-covered glacier, had suddenly released an estimated volume of $320000 \mathrm{~m}^{3}$ of water. Multitemporal analysis of Landsat imagery showed that the lake had existed for less than two years prior to drainage. The outburst occurred beneath the glacier surface. The most likely interpretation of the observed features is that a drainage channel within the glacier was suddenly blocked at the end of 2000 or in the beginning of 2001, allowing the development of the lake. With increasing lake size and therefore pressure, the blockage failed and the lake then drained suddenly.

The volume of debris deposited on the cone was estimated at $1.0-1.5$ million $\mathrm{m}^{3}$, meaning that the ratio between entrained debris and water would be $3-5$. This is a very high value compared to the ratio of $2-3$ suggested by Huggel et al. (2004b). However, an even higher ratio than observed for Dasht was reported by Breien et al. (2008) for a GLOF in Norway. Possibly, subglacial water reservoirs connected to the superficial lake were involved in both events.

These figures show that the characteristics of the Dasht event underwent pronounced changes during the flow, converting from a clear water runoff to a hyperconcentrated flow and finally to a granular debris flow. The event destroyed a large portion of the village of Dasht, killed dozens of people and dammed the Shakhdara river. It was reported that the flood wave arrived at Dasht in three stages, a phenomenon that can be explained by temporary backwater in the canyon of the lower transitional zone due to blockage of large boulders transported by the GLOF or by lateral slope failures followed by vigorous breakthroughs (Schneider et al., 2004). According to local people from the village of Baroj on the opposite side of the valley, the travel time from the onset of the process to Dasht was at least $45 \mathrm{~min}$.

The Dasht event was the only major GLOF reported from the Pamir in the past decades. However, several events are known from the Tien Shan, most recently the outbursts of the Archa-Bashy glacier lake in 1998 and of the western Zyndan glacier lake in 2008 (Narama et al., 2010).

\section{Lake inventory preparation}

This study relies primarily on remotely sensed data. In order to obtain a multi-temporal coverage of the entire study area, the following sets of satellite images were collected:

1. declassified Corona images (1968; pixel size $<5 \mathrm{~m}$ )

2. Landsat ETM+ images (2000-2003; pixel size $15 \mathrm{~m}$ pan-sharpened)

3. ASTER images (2000-2009; pixel size: $15 \mathrm{~m}$ )
In addition, the SRTM-4 digital elevation model (Jarvis et al., 2008; approx. $90 \mathrm{~m}$ pixel size) was used. Despite its coarser resolution, it appeared to better represent the real terrain than ASTER DEMs, a finding in line with Kääb et al. (2005).

All lakes in the area were mapped for three time windows: 1968 (Corona imagery), 2001/2002 (ASTER and pansharpened Landsat ETM+ imagery), and 2007/2008 (ASTER imagery). Except for 1968, it was not possible to cover the entire area with cloud- and snow-free scenes from one single year, let alone day. The verification and collection of additional information for each lake was supported by highresolution Google Earth scenes.

Dam material, type of drainage and the presence of glaciers calving into the lake were recorded for each lake. Seepage through the dam was assumed for all lakes without clearly recognizable surface drainage. Even though combinations and temporal changes of both types of lake drainage are common, a detailed analysis of this phenomenon is hardly applicable at the regional scale. Lake area $A\left(\mathrm{~m}^{2}\right)$ was derived and the freeboard $F(\mathrm{~m})$ was computed as the difference between the DEM with filled sinks and the elevation of the lake (value of original DEM for the lake centroid). Table 1 summarizes the key parameters assigned to each mapped lake. All lakes with $A<2500 \mathrm{~m}^{2}$ in 2007/2008 were excluded from further analysis.

Regression functions relating lake volume to lake area were suggested e.g. by O'Connor et al. (2001) and Huggel et al. (2002), and used by Allen et al. (2009). However, computing lake volume directly from lake area is problematic. The area is immanent to the volume and autocorrelation effects reduce the large scatter in the relation of measured area and depth and lead to an overestimation of the information quality (Huggel et al., 2002). Therefore, average lake depth was first derived from lake area using an empirical relationship developed by Huggel et al. (2002):

$D=1.04 \times 10^{-1} A^{0.42}$

In the next step, lake volume $V\left(\mathrm{~m}^{3}\right)$ was derived from lake area and average lake depth:

$V=D \times A=1.04 \times 10^{-1} A^{1.42}$

Lake area development was expressed as the lake area in 1968 resp. 2001/2002, related to the area in 2007/2008:

$r_{A 1}=\frac{A_{1968}}{A_{2007 / 2008}}$

$r_{A 2}=\frac{A_{2001 / 2002}}{A_{2007 / 2008}}$

Values below 1 indicate growth, values above 1 shrinkage of the lake. Values of 0 mean that the lake did not yet exist in 1968 resp. 2001/2002. Lakes existing in 1968 and/or $2001 / 2002$, but not in $2007 / 2008$, were disregarded in the analysis. 
Table 1. Parameters used as input for the regional-scale lake outburst hazard analysis (see Fig. 2).

\begin{tabular}{|c|c|c|c|}
\hline Parameter & Shortcut & Unit & Source \\
\hline $\begin{array}{l}\text { Lake drainage } \\
\text { Dam type } \\
\text { Possible calving into lake }\end{array}$ & & $\begin{array}{l}\text { boolean } \\
\text { nominal } \\
\text { boolean }\end{array}$ & $\begin{array}{l}\text { Qualitative interpretation of satellite imagery } \\
\text { (ASTER, WorldView, GoogleEarth) }\end{array}$ \\
\hline $\begin{array}{l}\text { Elevation a.s.l. } \\
\text { Freeboard }\end{array}$ & $\begin{array}{l}z \\
F\end{array}$ & $\begin{array}{l}\mathrm{m} \\
\mathrm{m}\end{array}$ & Computed from lake centroid and DEM \\
\hline Lake area & $A$ & $\mathrm{~m}^{2}$ & Derived from mapped lakes \\
\hline Average lake depth & $D$ & $\mathrm{~m}$ & Empirical relationship with lake area (Eq. 1) \\
\hline Lake volume & $V$ & $\mathrm{~m}^{3}$ & Derived from lake area and average lake depth (Eq. 2) \\
\hline $\begin{array}{l}\text { Lake area development } \\
\text { 1968-2007/2008 }\end{array}$ & $r_{A 1}$ & ratio & $\begin{array}{l}\text { Comparison of lake areas derived by multitemporal } \\
\text { analysis of satellite imagery }\end{array}$ \\
\hline $\begin{array}{l}\text { Lake area development } \\
2001 / 2002-2007 / 2008\end{array}$ & $r_{A 2}$ & & \\
\hline $\begin{array}{l}\text { Maximum Peak Ground } \\
\text { Acceleration }\end{array}$ & $\mathrm{PGA}_{\max }$ & $\mathrm{ms}^{-2}$ & $\begin{array}{l}\text { Map of active faults and published relationships } \\
\text { (Babaev et al., 1984; Abdrakhmatov et al., 2003) }\end{array}$ \\
\hline
\end{tabular}

As lake outburst floods are often related to major earthquakes, a surrogate for the seismic hazard was introduced: the maximum possible Peak Ground Acceleration $\mathrm{PGA}_{\max }\left(\mathrm{cm} \mathrm{s}^{-2}\right)$ was considered useful for this purpose. It was derived from a published map of active faults of Tajikistan (Babaev et al., 1984) and empirical relationships relating $\mathrm{PGA}_{\max }$ to the maximum earthquake magnitude assigned to the fault and the distance to the fault axis (Abdrakhmatov et al., 2003).

\section{Hazard analysis}

\subsection{Work flow}

The hazard analysis procedure applied to the regional scale is illustrated in Fig. 2. It aims at the identification of potentially hazardous lakes and possible impact areas of LOFs as a baseline for in-detail studies and risk mitigation procedures. The concept includes the hazard

1. of each lake to produce an outburst flood (lake outburst hazard $H$ );

2. of each pixel to be affected by an outburst flood from a certain lake (impact hazard HI).

The general difficulty of establishing frequencies for rare or singular events like lake outburst floods in combination with sparse historical data in the study area make a strictly quantitative approach inapplicable. The concept of susceptibility - understood as the tendency of a lake to produce an outburst flood resp. the tendency of an outburst flood to reach a certain area or pixel - is used, instead. It is combined with the maximum possible magnitude in order to derive a measure for the hazard. This developed and employed

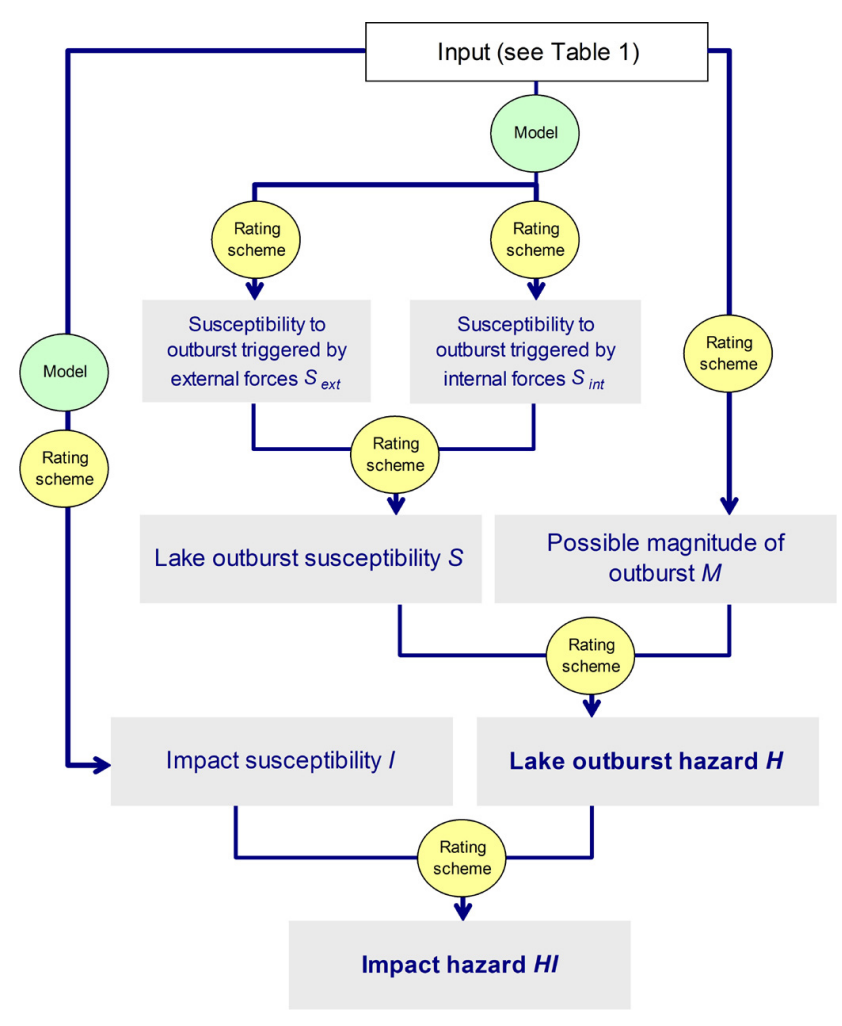

Fig. 2. Work flow of the regional-scale hazard analysis.

system of scoring and rating partly refers to work done by Reynolds (2003) and Huggel et al. (2004a) and is explained in the following sections.

The entire work flow is realized as a system of a shell and a C script making use of GRASS GIS, which is an Open Source Geographic Information Software, for the spatial 
Table 2. Rating scheme for susceptibility to outburst triggered by external forces $S_{\text {ext }}$. Initial values of $S_{\text {ext }}$ are determined from the topographic susceptibility index. These values are then increased or decreased according to the possibility of calving, seismic hazard and freeboard.

\begin{tabular}{lllr}
\hline Criterion & Class & Definition & $S_{\text {ext }}$ \\
\hline \multirow{3}{*}{ Topographic susceptibility index } & 1 Low & TSI $<10$ & 0 \\
& 2 Medium & TSI $\geq 10-<40$ & 1 \\
3 High & TSI $\geq 40$ & 2 \\
Calving into lake & 1 No calving possible & mapped & \pm 0 \\
\multirow{3}{*}{ Seismic hazard } & 2 Calving possible & mapped & +1 \\
& 1 Low & $\mathrm{PGA}_{\max }<500 \mathrm{~cm} \mathrm{~s}^{-2}$ & \pm 0 \\
Freeboard & 2 High & $\mathrm{PGA}_{\max } \geq 500 \mathrm{~cm} \mathrm{~s}^{-2}$ & +1 \\
& 1 High & $F>25 \mathrm{~m}$ & -1 \\
& 2 Low & $F \leq 25 \mathrm{~m}$ & \pm 0 \\
\hline
\end{tabular}

analysis components. The major spatial modelling tasks include the topographic Susceptibility Index TSI (see next section), the dam geometry and the area of impact. The DEM, a raster map with a unique ID for each lake, and a text file with the parameters listed in Table 1 for each lake are used as input. The output consists of a table with the lake outburst susceptibility and hazard ratings for each lake, as well as raster maps with lake-specific impact susceptibility and hazard ratings for each pixel.

The procedure is applied with a pixel size of $60 \mathrm{~m}$. The results are verified by testing the output of the entire procedure against the information available for the Dasht 2002 event and by in-depth investigations of selected cases. For this purpose, several helicopter and field missions were carried out in 2003 and 2009 in order to ensure a close and up-to-date survey of the lakes and valleys of interest.

\subsection{Lake outburst susceptibility and hazard}

\subsubsection{Susceptibility to lake outburst triggered by external forces}

The susceptibility to each lake to produce an outburst flood triggered by any kind of mass movement interfering with the lake or by an earthquake was investigated. The event at Laguna 513 in the Cordillera Blanca (Perú; Haeberli et al., 2010b), where an ice avalanche from far upslope caused a destructive flood wave on 11 April 2010, has shown the need to include the entire catchment in such an analysis, and not only the portion directly adjacent to the lake. The topographic susceptibility index TSI is introduced in order to account for this need: each pixel within the catchment of the lake is assigned to one of 25 predefined classes, based on the local slope and the average slope of the steepest path to the lake. Depending on the class, a topographic susceptibility rating TSR (with possible values $0-10$ ) is assigned to the pixel, describing the tendency of the lake to be affected by a mass movement originating from the respective pixel. The rating builds on a combination of classes of local slope for the onset and of the average slope of the potential flow path between onset area and lake for the motion of mass movements, following thresholds given e.g. by Corominas et al. (2003). In order to derive TSI for the entire catchment, the sum of the TSRs for each class is weighted by the surface area assigned to the respective class (possible weights: $1-4$ ). The weighted indices for each class are then summed up. The resulting maximum possible TSI is 212 . This concept does not account for local geological conditions, but provides a valuable estimate of where impacts are basically possible and where they are not.

TSI is the base for rating the susceptibility to lake outburst triggered by external forces $S_{\text {ext }}$ (Table 2). The possibility of ice calving into the lake is accounted for by increasing $S_{\text {ext }}$ by 1 for lakes with directly adjacent glaciers.

Regarding the probability of triggering events, too little high-altitude meteo data are available to be included in the rating. The Maximum Peak Ground Acceleration $\mathrm{PGA}_{\max }$ is used to account for the seismic hazard. PGA thresholds for the triggering of mass movements in different areas show a large scatter. The threshold of $0.7 \mathrm{~m} \mathrm{~s}^{-2}$ found out by Wang et al. (2010) for the Wenchuan 2008 earthquake relates to the extremely landslide-prone slopes of that area and is not applicable to the southwestern Pamir. Murphy et al. (2002) suggested thresholds between 4.5 and $20.4 \mathrm{~m} \mathrm{~s}^{-2}$ for the rocky slopes of the Tachia Valley in Taiwan. Holding to these findings, $S_{\text {ext }}$ is increased by 1 for $\mathrm{PGA}_{\max } \geq 5 \mathrm{~m} \mathrm{~s}^{-2}$.

The freeboard $F(\mathrm{~m})$ is computed from the DEM. For lakes with $F \geq 25 \mathrm{~m}$, the rating is decreased by 1 in order to derive the final rating (see Table 2). Therefore, $S_{\text {ext }}$ could take values between 0 and 4 (negative values are considered as 0 ). 
Table 3. Rating scheme for Susceptibility to lake outburst triggered by internal forces $S_{\text {int }}$. Initial values of $S_{\text {int }}$ are determined depending on the dam material. These values are then increased or decreased according to lake drainage, lake area development and downstream slope of the dam.

\begin{tabular}{lllr}
\hline Criterion & Class & Definition & $S_{\text {int }}$ \\
\hline \multirow{4}{*}{ Dam material } & 1 Embedded lake & mapped & 0 \\
& 2 Block dam & mapped & 0 \\
& 3 Debris dam & mapped & 1 \\
& 4 Rocky swell dam & mapped & 0 \\
Lake drainage & 1 Clacier or fresh moraine dam & mapped & 2 \\
& 2 No clearly recognizable surface drainage & mapped & \pm 0 \\
Lake area development & mapped & +1 \\
& 1 Stable or shrinking & $r_{A 1}$ and $r_{A 2}>0.8$ & \pm 0 \\
Downstream slope of dam & 2 Growing & $r_{A 1}$ or $r_{A 2} \leq 0.8$ & +1 \\
& 1 Gentle & $\tan \beta<0.02$ & -1 \\
& 2 Steep & $\tan \beta \geq 0.02$ & \pm 0 \\
\hline
\end{tabular}

\subsubsection{Susceptibility to lake outburst triggered by internal forces}

As directly measured quantitative data is not applicable at the regional scale, a qualitative rating for the susceptibility to lake outburst by internal forces (dam failure) $S_{\text {int }}$ has to be introduced, building on the following key parameters: (1) dam material; (2) lake drainage, (3) lake area development, and (4) dam geometry. Table 3 shows the applied rating scheme.

Dams with seepage are rated more susceptible to failure than dams with surface runoff only, and growing lakes are rated more susceptible than stable or shrinking ones. All lakes with a size of $\leq 80$ per cent of the 2007/2008 surface area in either 1968 or 2001/2002 are classified as growing.

Dam geometry is expressed as an idealized average downstream slope of the dam: the dam width $W$ is defined as the Euclidean distance between the lake outlet and the closest pixel along the downstream flow path with a lower elevation than the average lake bottom, using the average lake depth $D$. The tangent of the average slope of the dam in outflow direction, $\tan \beta$, is then derived as $D / W$. For very small downstream average slopes $(\tan \beta \leq 0.02)$, the rating is decreased by 1 (see Table 3 ).

Also $S_{\text {int }}$ can take values between 0 and 4 , negative values are considered as 0 .

\subsubsection{Derivation of lake outburst susceptibility and hazard}

The ratings for $S_{\text {int }}$ and $S_{\text {ext }}$ are combined using the rating scheme shown in Table 4. In order to derive a measure for the hazard, the resulting lake outburst susceptibility $S$ is combined with a measure for the potential event magnitude $M$. Lake volume $V$ or the expected peak discharge of an outburst flood $Q_{\mathrm{P}}$ would be most suitable, but they are derived by empirical equations only and are highly uncertain. The
Table 4. Lake outburst susceptibility rating $S$ : combination of $S_{\text {ext }}$ and $S_{\text {int }}$.

\begin{tabular}{llllll}
\hline$S_{\text {int }} \downarrow$ & \multicolumn{5}{c}{$S_{\text {ext }} \rightarrow$} \\
& 0 & 1 & 2 & 3 & 4 \\
\hline 0 & 0 & 1 & 2 & 3 & 4 \\
1 & 1 & 2 & 3 & 3 & 4 \\
2 & 2 & 3 & 3 & 4 & 5 \\
3 & 3 & 3 & 4 & 4 & 5 \\
4 & 4 & 4 & 5 & 5 & 6 \\
\hline
\end{tabular}

lake volume is directly related to the lake area $A$ (see Eqs. 1 and 2). Therefore, the well-known lake area appears to be the best surrogate for $M$. The rating for the lake outburst hazard $H$ is derived by combining the outburst susceptibility $S$ of each lake with its area class. The applied scheme is shown in Fig. 3.

\subsection{Impact susceptibility and hazard}

\subsubsection{Impact susceptibility}

Impact susceptibility $I$ is understood as the tendency of an outburst flood from a defined lake to affect a certain area or pixel. It disregards the lake outburst hazard $H$ which is included in the next step (impact hazard HI).

On the regional scale, empirical-statistical relationships are suitable for relating the travel distance $L$ or the average slope of reach $\omega$ of a flow to the involved volume $V$ or the peak discharge $Q_{\mathrm{p}}$, or just defining a global $\omega$. Table 5 shows some of these relationships developed for debris flows in general and lake outburst floods in particular. 


\begin{tabular}{l|l|l|l|l|l|l|l}
\hline \multicolumn{1}{|c|}{$\boldsymbol{S} \rightarrow$} & $\mathbf{0 ~ N e}$ & $\mathbf{1 ~ L o}$ & $\mathbf{2} \mathrm{Mo}$ & $\mathbf{3} \mathrm{Me}$ & $\mathbf{4 ~ H i}$ & $\mathbf{5 ~ V h}$ & $\mathbf{6 ~ E h}$ \\
\hline$A<5,000 \mathrm{~m}^{2}$ & $0 \mathrm{Ne}$ & $0 \mathrm{Ne}$ & $0 \mathrm{Ne}$ & $0 \mathrm{Ne}$ & $0 \mathrm{Ne}$ & $0 \mathrm{Ne}$ & $0 \mathrm{Ne}$ \\
\hline$A=5,000-<20,000 \mathrm{~m}^{2}$ & $0 \mathrm{Ne}$ & $1 \mathrm{Lo}$ & $1 \mathrm{Lo}$ & $2 \mathrm{Mo}$ & $2 \mathrm{Mo}$ & $2 \mathrm{Mo}$ & $3 \mathrm{Me}$ \\
\hline$A=20,000-<40,000 \mathrm{~m}^{2}$ & $0 \mathrm{Ne}$ & $1 \mathrm{Lo}$ & $2 \mathrm{Mo}$ & $3 \mathrm{Me}$ & $3 \mathrm{Me}$ & $3 \mathrm{Me}$ & $4 \mathrm{Hi}$ \\
\hline$A=40,000-<100,000 \mathrm{~m}^{2}$ & $0 \mathrm{Ne}$ & $2 \mathrm{Mo}$ & $3 \mathrm{Me}$ & $3 \mathrm{Me}$ & $3 \mathrm{Me}$ & $4 \mathrm{Hi}$ & $4 \mathrm{Hi}$ \\
\hline$A=100,000-<250,000 \mathrm{~m}^{2}$ & $0 \mathrm{Ne}$ & $2 \mathrm{Mo}$ & $3 \mathrm{Me}$ & $4 \mathrm{Hi}$ & $4 \mathrm{Hi}$ & $5 \mathrm{Vh}$ & $5 \mathrm{Vh}$ \\
\hline$A=250,000-<1,000,000 \mathrm{~m}^{2}$ & $0 \mathrm{Ne}$ & $2 \mathrm{Mo}$ & $3 \mathrm{Me}$ & $4 \mathrm{Hi}$ & $5 \mathrm{Vh}$ & $5 \mathrm{Vh}$ & $6 \mathrm{Eh}$ \\
\hline$A \geq 1,000,000 \mathrm{~m}^{2}$ & $0 \mathrm{Ne}$ & $3 \mathrm{Me}$ & $4 \mathrm{Hi}$ & $4 \mathrm{Hi}$ & $5 \mathrm{Vh}$ & $6 \mathrm{Eh}$ & $6 \mathrm{Eh}$
\end{tabular}

Fig. 3. Lake outburst hazard $H$ : combination of lake area as surrogate for the possible lake outburst magnitude $M$ and susceptibility $S$. Ne=negligible, Lo=low, Mo=moderate, $\mathrm{Me}=$ medium, $\mathrm{Hi}=$ high, $\mathrm{Vh}=$ very high, $\mathrm{Eh}=$ extremely high.

Corominas et al. (2003) found an average angle of reach of $\omega=21^{\circ}$ for debris flows on unobstructed flow paths. Rickenmann (1999) related the horizontal travel distance $L(\mathrm{~m})$ to the bulk volume of the flow $V\left(\mathrm{~m}^{3}\right)$ and the vertical distance $Z$ (m) (see Table 5). The results obtained by these rules show a large scatter among themselves and generally underestimate the travel distance of LOFs (Mergili et al., 2011; Fig. 4). Haeberli (1983) suggested $\omega=11^{\circ}$ specifically for GLOFs, which was applied by Huggel et al. (2003) in combination with the Modified Single Flow direction model (MSF).

Several authors have proposed empirical relationships for deriving the peak discharge $Q_{\mathrm{p}}\left(\mathrm{m}^{3} \mathrm{~s}^{-1}\right)$ - required as input for the relationship T3 in Table 5 - based on outburst volume $V\left(\mathrm{~m}^{3}\right)$ and dam height $D(\mathrm{~m})$ as predictors, see e.g. Crosta et al. (2006) for an overview. In the present study, the outburst volume is set as equal to the lake volume (worstcase assumption). Table 6 summarizes various approaches, mainly regression functions. Walder and Costa (1996) and Huggel et al. (2004a) emphasized the importance to distinguish between different drainage modes and different types of dams, respectively. $t$ in the relationship Q8 stands for the duration of the outburst, Huggel et al. (2004a) suggest to set $t=1000 \mathrm{~s}$ as a first approximation.

After the deposition of the debris or mud carried by the LOF, or if not much sediment is entrained at all, the flood may propagate much farther: Haeberli (1983) suggested an average angle of reach of $2-3^{\circ}$, but also travel distances exceeding $200 \mathrm{~km}$ were reported (e.g. Hewitt, 1982).

In order to achieve a robust estimate of the travel distance of potential LOFs, the approaches T1-T4 shown in Table 5 are combined. The approach of Corominas et al. (2003) is disregarded as it is apparently not at all suitable for LOFs. The susceptibility of each pixel to be affected by an outburst flood from the respective lake is computed as follows, making use of GRASS GIS:

\begin{tabular}{c|c|c|c|c|c|c|c}
$\boldsymbol{H} \downarrow \boldsymbol{I} \rightarrow$ & $\mathbf{0 ~ N e}$ & $\mathbf{1} \mathbf{L o}$ & $\mathbf{2} \mathbf{M o}$ & $\mathbf{3} \mathbf{M e}$ & $\mathbf{4} \mathbf{H i}$ & $\mathbf{5} \mathbf{V h}$ & $\mathbf{6 ~ E h}$ \\
\hline $\mathbf{0} \mathbf{N e}$ & $0 \mathrm{Ne}$ & $0 \mathrm{Ne}$ & $0 \mathrm{Ne}$ & $0 \mathrm{Ne}$ & $0 \mathrm{Ne}$ & $0 \mathrm{Ne}$ & $0 \mathrm{Ne}$ \\
\hline $\mathbf{1} \mathbf{L o}$ & $0 \mathrm{Ne}$ & $1 \mathrm{Lo}$ & $1 \mathrm{Lo}$ & $2 \mathrm{Mo}$ & $2 \mathrm{Mo}$ & $2 \mathrm{Mo}$ & $3 \mathrm{Me}$ \\
\hline $\mathbf{2} \mathbf{M o}$ & $0 \mathrm{Ne}$ & $1 \mathrm{Lo}$ & $2 \mathrm{Mo}$ & $3 \mathrm{Me}$ & $3 \mathrm{Me}$ & $3 \mathrm{Me}$ & $4 \mathrm{Hi}$ \\
\hline $\mathbf{3} \mathbf{M e}$ & $0 \mathrm{Ne}$ & $2 \mathrm{Mo}$ & $3 \mathrm{Me}$ & $3 \mathrm{Me}$ & $3 \mathrm{Me}$ & $4 \mathrm{Hi}$ & $4 \mathrm{Hi}$ \\
\hline $\mathbf{4} \mathbf{H i}$ & $0 \mathrm{Ne}$ & $2 \mathrm{Mo}$ & $3 \mathrm{Me}$ & $4 \mathrm{Hi}$ & $4 \mathrm{Hi}$ & $5 \mathrm{Vh}$ & $5 \mathrm{Vh}$ \\
\hline $\mathbf{5} \mathbf{V h}$ & $0 \mathrm{Ne}$ & $2 \mathrm{Mo}$ & $3 \mathrm{Me}$ & $4 \mathrm{Hi}$ & $5 \mathrm{Vh}$ & $5 \mathrm{Vh}$ & $6 \mathrm{Eh}$ \\
\hline $\mathbf{6} \mathbf{E h}$ & $0 \mathrm{Ne}$ & $3 \mathrm{Me}$ & $4 \mathrm{Hi}$ & $4 \mathrm{Hi}$ & $5 \mathrm{Vh}$ & $6 \mathrm{Eh}$ & $6 \mathrm{Eh}$
\end{tabular}

Fig. 4. Matrix for the impact hazard $\mathrm{HI}$ rating based on the ratings for lake outburst hazard rating $H$ and impact susceptibility $I$. The abbreviations are explained in the legend of Fig. 3.

1. The lake outburst flood is considered as one single mass point, starting from the outlet of the respective lake. It is routed downstream following a random walk approach weighted for the local slope angle. In order to cover all possible pathways, 800 random walks are performed for each lake.

2. At the start of each random walk, the empirical relationship defining the travel distance is determined randomly, choosing among T1-T4 (see Table 5). This means that \pm 200 random walks are performed according to each of the relationships. For T1, the volume $V$ is randomly varied between one time and four times the lake volume in order to account for bulking with sediment. Regarding T3, $Q_{\mathrm{p}}$ is chosen randomly from Table 6 for each random walk. Q1-Q9 are used for glacial lakes (Type 5 in Table 3). For all other lakes, only the relationships Q1-Q7 are used. This leads to the representation of all the relationships in the results $( \pm 25-30$ random walks per relationship).

3. An impact susceptibility rating $I$ ( 0 negligible-6 extremely high) is then assigned to each pixel, based on the number $n$ of relationships T1-T4 predicting an impact for the corresponding pixel, and on the average slope $\omega$ (Table 7). With $n=1$, the corresponding relationship would always be T4, yielding the longest travel distance and the largest impact area. For these pixels, the possible type of impact is considered as a flood (no debris flow), and the impact susceptibility rating $I$ is 1 low-3 medium, depending on $\omega$. If at least two of the relationships predict an impact on the pixel, also debris flow is considered as possible impact type, and the impact susceptibility is defined 4 high-6 extremely high, depending on $n$. 
Table 5. Empirical relationships potentially suitable for estimating the travel distance of lake outburst floods.

\begin{tabular}{llll}
\hline & Relationship & References & Remarks \\
\hline T1 & $L=1.9 V^{0.16} Z^{0.83}$ & Rickenmann (1999) & for debris flows in general \\
\hline T2 & $\omega=11^{\circ}$ & $\begin{array}{l}\text { Haeberli (1983), } \\
\text { Huggel et al. (2003), } \\
\text { Huggel et al. (2004a) }\end{array}$ & $\begin{array}{l}\text { for debris flows from GLOFs, applied } \\
\text { with } \omega .5^{\circ} \text { in the present paper }\end{array}$ \\
\hline T3 & $\omega=18 Q_{\mathrm{p}}^{-0.07}$ & Huggel (2004) & worst case for debris flows from GLOFs \\
\hline T4 & $\omega \geq 2^{\circ}$ & Haeberli (1983), & for floods from GLOFs \\
& & Huggel et al. (2004a) & \\
\hline
\end{tabular}

Table 6. Empirical equations relating peak discharge $Q_{\mathrm{p}}$ to outburst volume $V$ and lake depth resp. dam height $D$. $\rho_{w}=$ density of water $\left(\mathrm{kg} \mathrm{m}^{-2}\right), g=$ gravity $\left(\mathrm{m} \mathrm{s}^{-2}\right)$. The examples refer to the computed peak discharges of the Dasht event 2002 (lake area: $\left.37000 \mathrm{~m}^{2}\right)$ and a hypothetic complete drainage of Rivakkul $\left(1.2 \mathrm{~km}^{2}\right)$.

\begin{tabular}{lllll}
\hline & Equation for $Q_{\mathrm{p}}\left(\mathrm{m}^{3} \mathrm{~s}^{-1}\right)$ & Reference & $\begin{array}{l}\text { Example } Q_{\mathrm{p}} \\
\text { Dasht } 2002\end{array}$ & $\begin{array}{l}\text { Example } Q_{\mathrm{p}} \\
\text { Rivakkul }\end{array}$ \\
\hline Q1 & $672\left(10^{-6} V\right)^{0.56}$ & Costa $(1985)$ & $354 \mathrm{~m}^{3} \mathrm{~s}^{-1}$ & $5562 \mathrm{~m}^{3} \mathrm{~s}^{-1}$ \\
Q2 & $6.3 D^{1.59}$ & & $194 \mathrm{~m}^{3} \mathrm{~s}^{-1}$ & $1955 \mathrm{~m}^{3} \mathrm{~s}^{-1}$ \\
Q3 & $181\left(10^{-6} V \cdot D\right)^{0.43}$ & & $280 \mathrm{~m}^{3} \mathrm{~s}^{-1}$ & $4329 \mathrm{~m}^{3} \mathrm{~s}^{-1}$ \\
\hline Q4 & $1.58 \cdot 10^{-2}\left(\rho_{W} \cdot g \cdot V \cdot D\right)^{0.41}$ & Costa and Schuster $(1988)$ & $299 \mathrm{~m}^{3} \mathrm{~s}^{-1}$ & $4072 \mathrm{~m}^{3} \mathrm{~s}^{-1}$ \\
\hline Q5 & $1.6 V^{0.46}$ & Walder and O'Connor $(1997)$ & $544 \mathrm{~m}^{3} \mathrm{~s}^{-1}$ & $5225 \mathrm{~m}^{3} \mathrm{~s}^{-1}$ \\
Q6 & $6.7 D^{1.73}$ & & $278 \mathrm{~m}^{3} \mathrm{~s}^{-1}$ & $3446 \mathrm{~m}^{3} \mathrm{~s}^{-1}$ \\
Q7 & $9.9 \cdot 10^{-1}(V \cdot D)^{0.40}$ & & $373 \mathrm{~m}^{3} \mathrm{~s}^{-1}$ & $4766 \mathrm{~m}^{3} \mathrm{~s}^{-1}$ \\
\hline Q8 & $2 V / t$ for moraine dams & Huggel et al. (2004a) & $638 \mathrm{~m}^{3} \mathrm{~s}^{-1}$ & \\
Q9 & $46\left(10^{-6} V\right)^{-0.07}$ for ice dams & & $50 \mathrm{~m}^{3} \mathrm{~s}^{-1}$ & \\
\hline
\end{tabular}

\subsubsection{Impact hazard}

The ratings for lake outburst hazard $H$ and impact susceptibility $I$ are combined to a rating of the impact hazard HI according to the matrix shown in Fig. 4. A first step towards risk analysis is taken by an overlay of the impact hazard map with a map of settlements and cultivated areas. A further differentiation of this map regarding exposure and vulnerability would be required for a full regional-scale risk analysis.

\subsection{Evaluation with the Dasht 2002 event}

The hazard analysis procedure is evaluated using the Dasht 2002 event. In its surface appearance, the lake did not differ substantially from many other glacial lakes in the study area. The lake outburst susceptibility is rated very high, the hazard - due to the limited size of the lake - only as medium.

All empirical models shown in Table 5 underestimate the travel distance of the debris flow of Dasht, which is characterized by $\omega=9.3^{\circ}$. Whilst the resulting debris flow had reached the village of Dasht $10.5 \mathrm{~km}$ downstream from the lake, the empirical relationships predict the debris flow to stop already in the upper portion of the catchment (Fig. 5). The reasons for the long travel distance might be a mobilized subglacial water reservoir involved in the flow, a particular flow rheology, or backwater effects: according to field observations and interviews with the local population, a blockage of a narrow channel section occurred at least twice, followed by vigorous releases of water, debris and mud (Schneider et al., 2004).

In order to get more conservative values - as desired in this type of analysis - a value of $\omega=8.5^{\circ}$ is used when applying relationship T2 to the southwestern Pamir (see Table 5). 
Table 7. Impact susceptibility rating $I . n$ stands for the number of relationships (see Table 5) predicting an impact on the considered pixel, $\omega$ stands for the average slope angle from the lake to the considered pixel. Since the relationship designed for floods predicts the longest travel distance and not all LOFs evolve into debris flows, the impact type for pixels with $n \geq 2$ can be flood or debris flow.

\begin{tabular}{llll}
\hline$I$ & $n$ & $\omega$ (degree) & type of impact \\
\hline 0 Negligible & 0 & & \\
\hline 1 Low & 1 & $\begin{array}{l}<4 \\
4-<6\end{array}$ & flood \\
2 Moderate & & \\
3 Medium & & $\geq 6$ & \\
\hline 4 High & 2 & not applicable & debris flow or flood \\
5 Very high & 3 & & \\
6 Extremely high & 4 & & \\
\hline
\end{tabular}

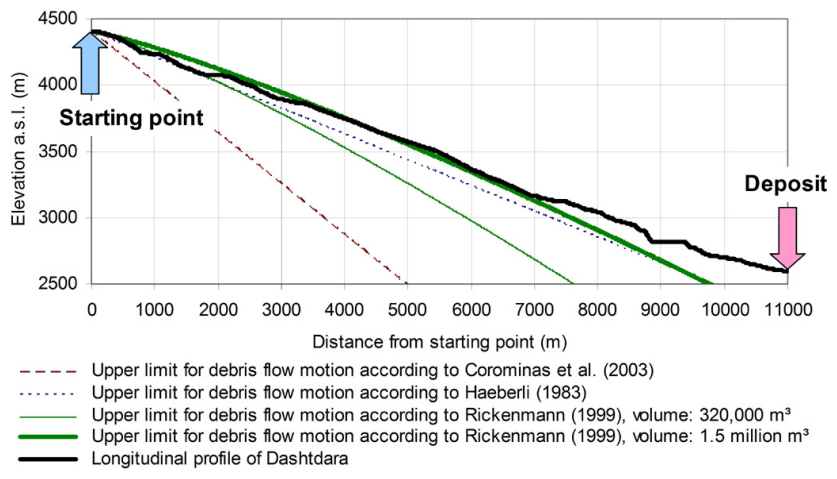

Fig. 5. Longitudinal profile of the flow path of the Dasht 2002 event with the upper limits of the flow paths according to different empirical relationships.

\section{Results}

\subsection{Distribution and characteristics of lakes}

For the period 2007/2008, 428 lakes with $A \geq 2500 \mathrm{~m}^{2}$ have been identified in the study area. 20 of them are just widened portions of rivers or shallow swampy lakes (recognized by topographic situation, colour and the existence of gravel bars) and are excluded from further analysis. Among the 408 remaining lakes, 187 are embedded in undulating landscapes most likely formed during the Pleistocene, at some distance from recent glaciers but still above $4000 \mathrm{~m}$ a.s.l (Type 1 in Table 3). 20 lakes have dams dominated by coarse blocks, representing Pleistocenic terminal moraines, landslide deposits or a combination of both (Type 2). 13 lakes are dammed by talus or debris cones (Type 3 ) and 16 by pronounced rocky swells (Type 4). The remaining 172 lakes represent glacial lakes in the strict sense: they are either directly embedded in the exposed ice, or dammed by debris-covered glacier tongues, rock glaciers or fresh moraines (Type 5). The tran-

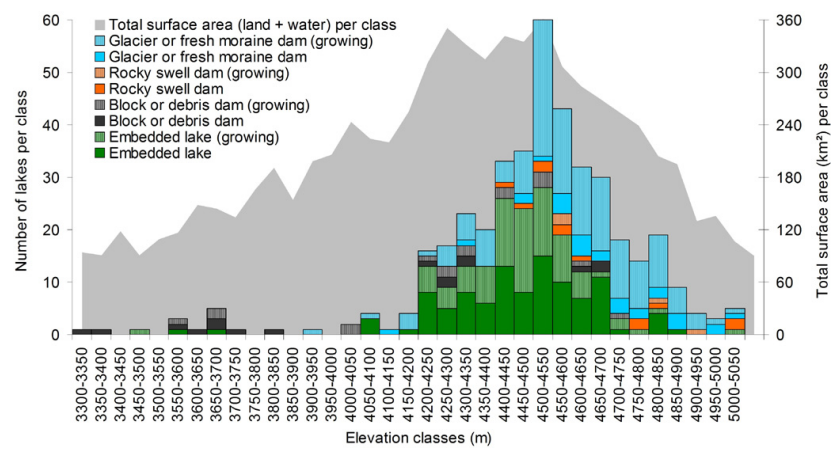

Fig. 6. Distribution of lake types and lake evolution plotted against elevation. The distribution of the total surface of the study area is shown as reference.

sition between the latter three types is rather gradual than sharp and the identification requires geophysical methods not applicable at the regional scale. No distinction is therefore made between pro- and supraglacial lakes. Table 8 summarizes the numbers and some geometric characteristics of the different lake types.

Figure 6 plots the altitudinal distribution of the lakes, organized by dam types. Less than 10 per cent of all lakes are found below $4200 \mathrm{~m}$ a.s.l., but two of them are larger than $1 \mathrm{~km}^{2}$ (Durumkul and Rivakkul; Type 2). At approx. $4200 \mathrm{~m}$ a.s.l., the steep valley flanks give way to the undulating plains formed by Pleistocenic glaciers. The latter landscape hosts numerous lakes of Type 1. Turumtaikul and Zaroshkul are the largest representatives of this type. Above $4500 \mathrm{~m}$ a.s.l., in the zone of recent glaciers and fresh moraines, lakes of Type 5 become more abundant and dominate the zone from $4700 \mathrm{~m}$ upwards. The highest identified glacial lakes are located at $5060 \mathrm{~m}$ a.s.l. The highest density of lakes is found at $4500-4550 \mathrm{~m}$ a.s.l. Reasons are the large share of the land area in this class on the one hand (see Fig. 6) and the presence of favourable conditions for the development of lakes of Type 1 and 5 on the other hand.

Figure 6 also shows the trends in lake development. Most glacial lakes (Type 5), located in a changing environment with active morphodynamics, are growing, as are many lakes of Type 1 .

\subsection{Lake outburst susceptibility}

There is no significant differentiation of lake types regarding the susceptibility to lake outburst triggered by external forces $S_{\text {ext }}$, which rather depends on the topography and state of the adjacent slopes than on the dams themselves (Fig. 7a). Glacial lakes are most susceptible to outbursts triggered by internal forces, as prescribed by the rating scheme (Fig. 7b). In sum, glacial lakes are by far the most susceptible, with 66 cases of very high susceptibility (Class 5) and 85 cases of high susceptibility (Class 4). There are also 15 non-glacial 
Table 8. Lake statistics, organized by lake type. $n_{l}=$ number of lakes, $p_{\mathrm{g}}=$ percentage of growing lakes, $A_{\mathrm{avg}}$ and $A_{\mathrm{max}}=$ average resp. maximum lake area, $z_{\min }, z_{\mathrm{avg}}$ and $z_{\max }=$ minimum, average and maximum elevation a.s.1.

\begin{tabular}{lrcccccc}
\hline Lake type & $n_{1}$ & $p_{\mathrm{g}}$ & $A_{\text {avg }}\left(\mathrm{km}^{2}\right)$ & $A_{\max }\left(\mathrm{km}^{2}\right)$ & $z_{\min }(\mathrm{m})$ & $z_{\text {avg }}(\mathrm{m})$ & $z_{\max }(\mathrm{m})$ \\
\hline 1 Embedded lake & 187 & 45 & 0.143 & 8.99 & 3473 & 4460 & 5029 \\
2 Block dam & 20 & 55 & 0.205 & 1.68 & 3341 & 4076 & 4718 \\
3 Debris dam & 13 & 46 & 0.085 & 0.62 & 3590 & 4223 & 4686 \\
4 Rocky swell dam & 16 & 25 & 0.107 & 0.48 & 4418 & 4692 & 5021 \\
5 Glacier or fresh moraine dam & 172 & 83 & 0.018 & 0.41 & 3926 & 4608 & 5063 \\
\hline
\end{tabular}

lakes with high susceptibility. All other lakes are assigned to Class 3 (medium susceptibility) or lower (Fig. 7c).

\subsection{Lake outburst hazard and Impact hazard}

Among the 408 analyzed lakes, the lake outburst hazard $H$ for 122 is classified as negligible (Class 0 ) for most of them, due to their limited size of $A<5000 \mathrm{~m}^{2}$ (Fig. 7d). 35 lakes are assigned to Class 1 (low hazard), 124 to Class 2 (moderate hazard), 87 to Class 3 (medium hazard), 34 to Class 4 (high hazard) and 6 to Class 5 (very high hazard). No lakes are assigned to Class 6 (extremely high hazard). Glacial lakes are more prominent regarding susceptibility than hazard, as they are on average smaller than lakes of the other classes (see Table 8). In contrast, the large Durumkul with a surface area of $1.7 \mathrm{~km}^{2}$ and Rivakkul with $1.2 \mathrm{~km}^{2}$, dammed by deposits of large blocks (landslide deposits or Pleistocenic moraines), are both rated hazardous despite moderate and medium lake outburst susceptibility, respectively.

Figure 8 shows the hazard indication map for the entire study area. The lake outburst hazard for each lake and the impact hazard for each pixel are shown. The maximum travel distances of potential debris flows and floods emanating from the lakes are plotted in Fig. 9. Only for 97 out of the 408 lakes, debris flows exceeding a travel distance of $2 \mathrm{~km}$ are predicted in case of an outburst. The maximum value $(15.5 \mathrm{~km})$ is computed for Nimatskul (Lake N1 in Fig. 8; see next section). Flooding could proceed for more than $30 \mathrm{~km}$ in the case of 298 lakes, with a maximum of $75.5 \mathrm{~km}$. However, it has to be kept in mind that the only criterion used for the travel distance of floods is the average slope of the flow path. Many lakes in the study area are too small to produce floods reaching that far.

\subsection{Case studies}

The Dasht event is the only documented LOF in the study area. There is evidence for earlier outburst floods e.g. of Rivakkul (Schneider et al., 2004), but the observations are too vague to be used as a reference.

The lakes identified as hazardous or very hazardous can be organized into two categories:
1. growing glacial lakes (Type 5), mostly with seepage through the dam;

2. large lakes of various types (Type 1,2 and 4 according to Table 3).

Whilst it would be out of scope of the present paper to discuss all of those lakes in detail, one example of each type will be shown in order to illustrate the specific potentials and limitations of the regional-scale analysis procedure when zooming into a more detailed level.

A growing glacial lake (Lake V1) is located in the upper reaches of Varshedzdara at $4513 \mathrm{~m}$ a.s.l. (Fig. 10a and b; see Fig. 8), $11 \mathrm{~km}$ upstream of the village of Varshedz. In summer 2007, the lake had a surface area of $155000 \mathrm{~m}^{2}$. Lake outburst susceptibility and hazard are rated very high. Lake V1 serves as an example for many similar glacial lakes in the study area, most of which are, however, smaller. A second, larger lake $\left(360000 \mathrm{~m}^{2}\right)$ of stable size (Lake V2) is located $2.5 \mathrm{~km}$ upstream from Lake V1, at $4795 \mathrm{~m}$ a.s.l. It is dammed by a rocky swell partly covered by morainic material and bordered by steep, partly glacierized slopes. It has no permanent surface drainage. The lake outburst susceptibility was rated medium, the lake outburst hazard high. An ice avalanche into the lake would be the most likely scenario to cause a flood wave. However, only a fraction of the lake would drain in such a case.

A LOF from Lake V2 would possibly hit Lake V1, which depending on the specific characteristics of the flow - could either level out or amplify the flood. Such effects are not accounted for by the empirical approaches used for impact susceptibility at the regional scale. Instead, travel distance, impact susceptibility and hazard are computed separately for each of the lakes. The empirical relationships suggest that a debris flow resulting from an outburst of Lake V1 or Lake V2 would not reach the village of Varshedz. A debris flow from Lake V2 would proceed farther $(11.0 \mathrm{~km})$ than one from Lake V1 $(3.5 \mathrm{~km})$ due to the larger maximum outburst volume and the steep initial slope. However, substantial flooding would have to be expected in the village of Varshedz (Fig. 10c). $43.9 \mathrm{~km}$ (Lake V1) resp. $50.1 \mathrm{~km}$ (Lake V2) are suggested as maximum travel distances of floods resulting from lake outbursts. When summing up the impact hazard 
a)

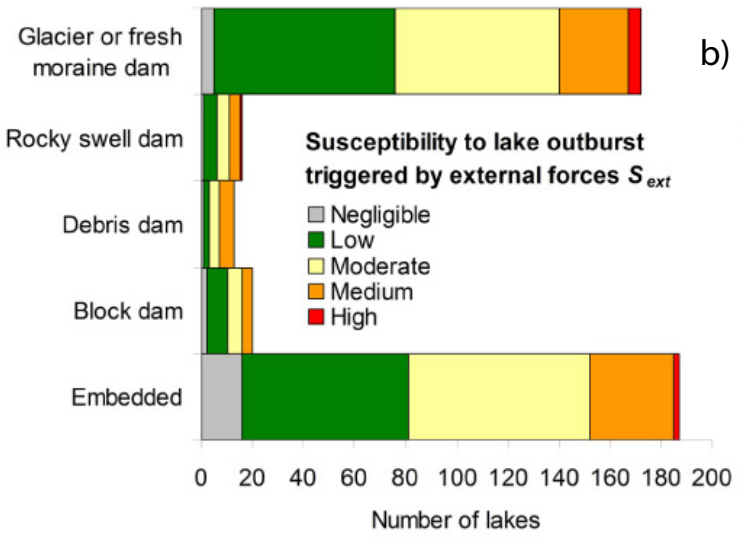

C)

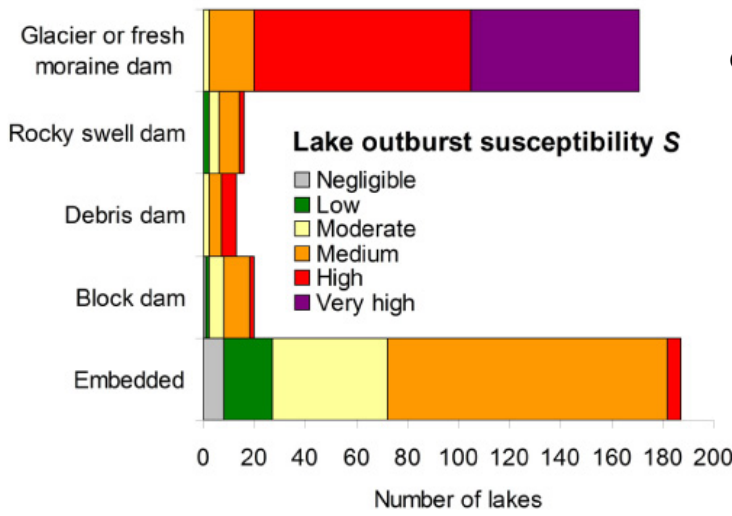

b)

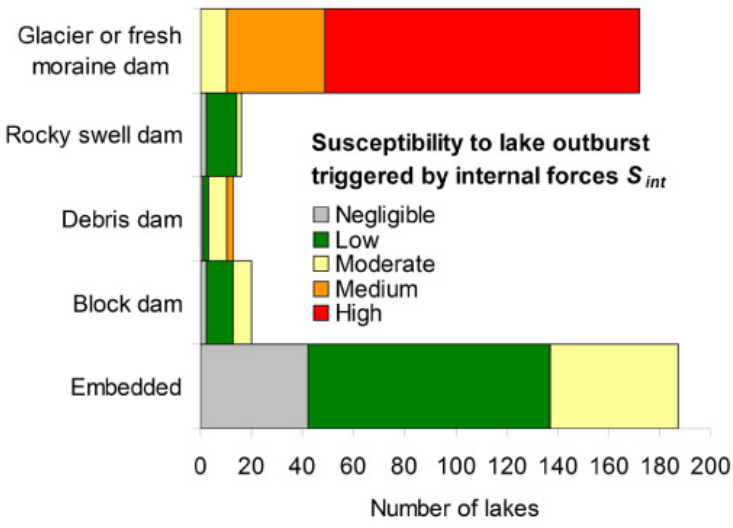

d)

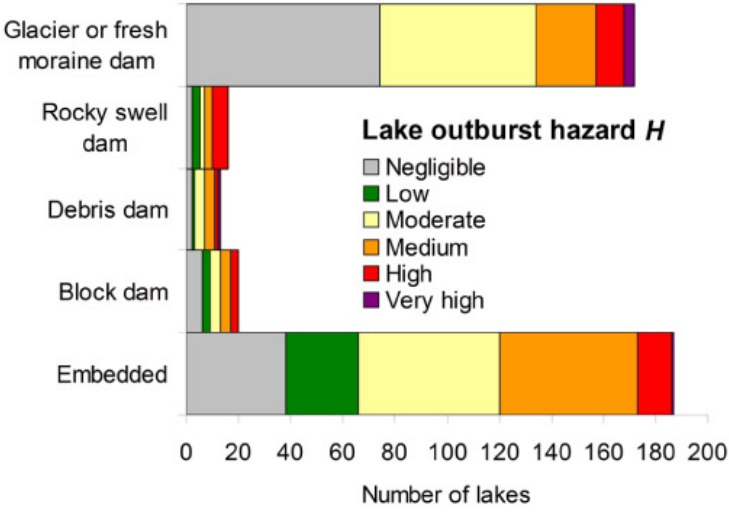

Fig. 7. (a) Susceptibility to lake outburst triggered by external forces $S_{\text {ext. }}$ (b) Susceptibility to lake outburst triggered by internal forces $S_{\text {int }}$. (c) Combined lake outburst susceptibility $S$. (d) Lake outburst hazard $H$.

HI for all pixels defined as settlement or agricultural area, Lake V1 and Lake V2 show much higher values than all the other lakes in the study area, mainly due to the location of the village of Varshedz directly on the debris cone where the flow would be expected to spread.

Among all the lakes in the study area, Nimatskul (Lake N1; Fig. 11a) is closest to the villages in the main valley. Located at $4418 \mathrm{~m}$ a.s.1., the horizontal distance from the lake down to the Gunt Valley is only $5.9 \mathrm{~km}$, with a vertical difference of $1600 \mathrm{~m}$. The steep average slope of the flow path $\left(\omega=15.2^{\circ}\right)$ and the availability of erodible material suggest that a possible outburst flood would most probably severely affect the villages near the outlet of the Nimatsdara (Fig. 11b).

The lake is dammed by a rocky swell and has a constant surface area of $475000 \mathrm{~m}^{2}$. Lake outburst susceptibility and hazard were rated medium and high, respectively. Sudden drainage of the lake may be caused by a powerful earthquake weakening the dam or leading to landslides into the lake. However, a closer on-site inspection of the slopes leading directly into the lake gave no evidence of large-scale instabilities, so that in reality, $S_{\text {ext }}$ and $H$ would be lower than suggested in the regional-scale analysis. Even though the slopes are obviously under permafrost conditions (see Fig. 11a), mass movements capable of displacing a substantial portion of the lake would require a very powerful trigger. With some limitations, similar conclusions can be drawn for Durumkul and Rivakkul.

\section{Discussion}

Even though the population of the Pamir directly depends on the natural environment and a lot of traditional knowledge exists (Kassam, 2009), lake outburst hazards are often neglected: the source area is usually far away from the area of impact and events occur at very long time intervals or as singularities. The Dasht 2002 GLOF hit the village completely unexpected - there was no awareness of the hazard and no preparedness for the event (Schneider et al., 2004). Also in other mountain areas, deficiencies in risk communication are often responsible responsible for the evolution of natural processes into disasters (Carey, 2005).

A regional-scale hazard analysis for the southwestern Pamir has been presented in order to highlight potentially 


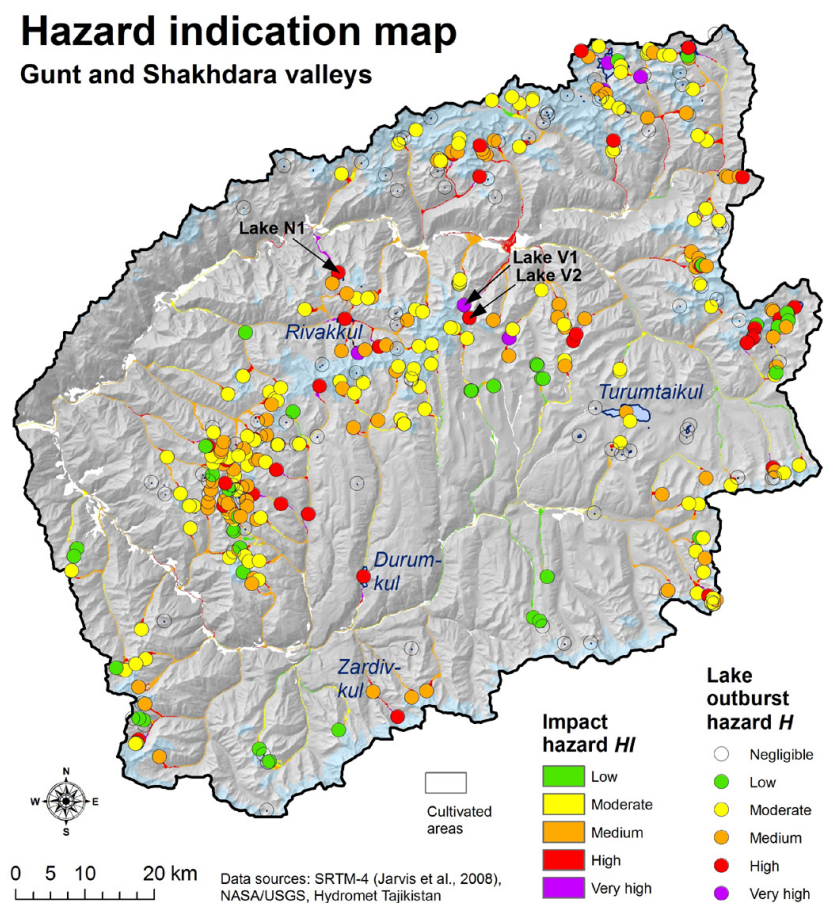

Fig. 8. Hazard indication map for the Gunt and Shakhdara valleys.

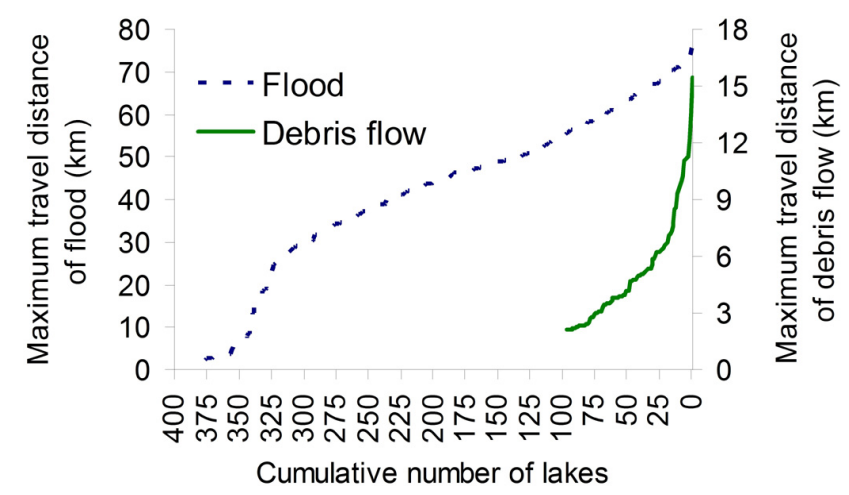

Fig. 9. Computed maximum travel distances of debris flows and floods from lake outbursts.

hazardous lakes and possible impact areas, building largely on medium-resolution satellite imagery and elevation data. The predictive capacity of such an analysis is governed primarily by the applicability of various types of input data: satellite imagery and digital elevation models only provide information on surface features and patterns, not allowing for insight beneath. Two aspects have turned out to be the major limiting factors of regional-scale lake outburst hazard analyses:

1. geological information. Rock types and major faults can be obtained from geological maps, but slope stability is often governed by small-scale dip directions and fault systems. Such features can be considered for single slopes or small catchments, but not at the regional scale. a)

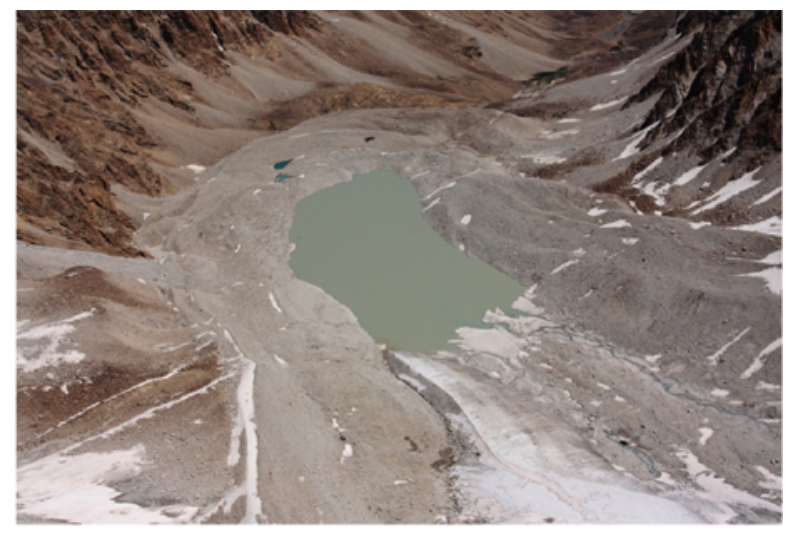

b)

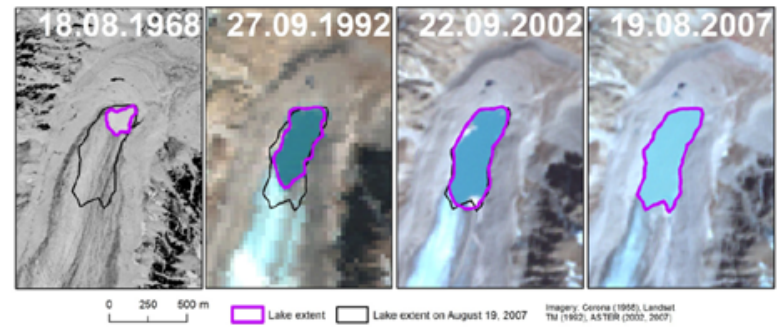

c)

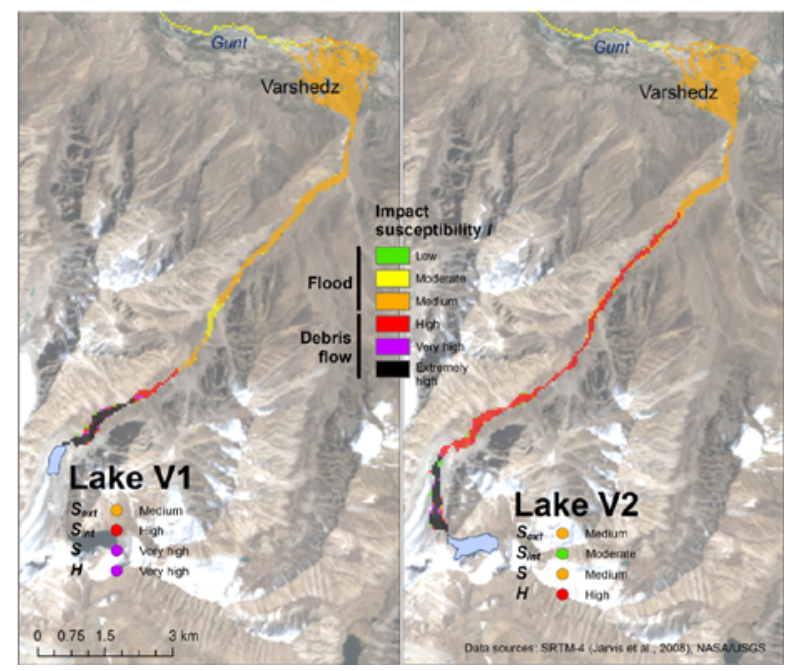

Fig. 10. (a) Aerial view of Lake V1 (August 2009). (b) Development of Lake V1 1968-2007. (c) Impact susceptibilities $I$ for potential outbursts of

Lake V1 and Lake V2.

Therefore, no geological input was used for computing TSI;

2. information on seepage through the dam and on its internal structure, particularly sediment consolidation, porosity (cavities) and subsurface ice content. Geophysical surveys (e.g. geoelectrics) are not feasible at a level broad enough to cover all relevant lakes.

Furthermore, the SRTM-4 DEM and the pixel size used $(60 \mathrm{~m})$ are insufficient to represent all relevant features: particularly for small lakes, the freeboard or the downstream 


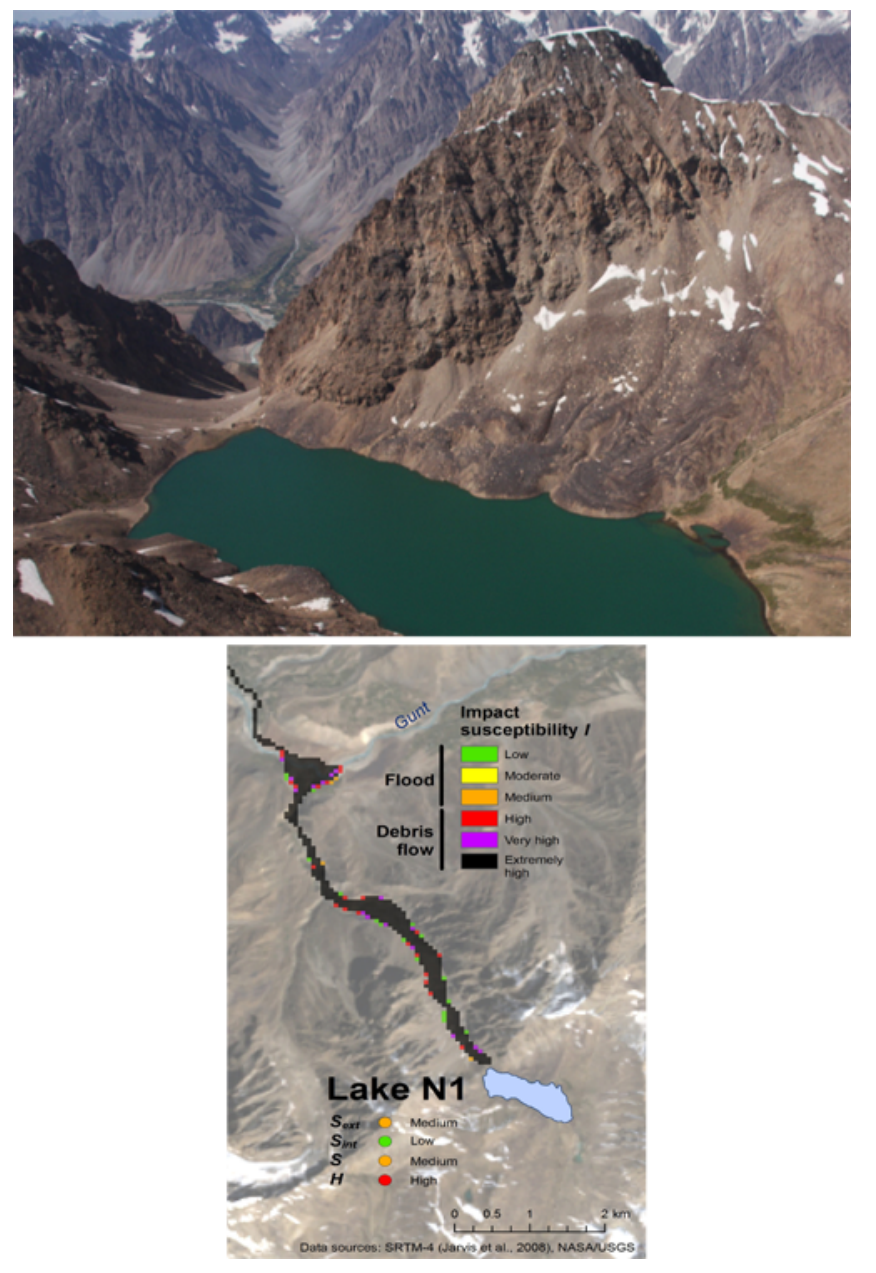

Fig. 11. (a) Aerial view of Lake N1 (Nimatskul) in August 2009, the Gunt Valley in the background. The viscous creep into the lake indicates that also the above rock wall is influenced by permafrost. (b) Modelled impact susceptibility $I$ of a potential outburst of $\mathrm{Ni}$ matskul.

slope of dams may be blurred. High-resolution DEMs are hardly applicable to regional-scale studies of this type, but a more thorough evaluation of the entire analysis procedure for a small test area with a high-resolution DEM and directly measured data (e.g. lake depth) would be an important next step.

The rating schemes used for the hazard analysis were tuned in a way to provide worst-case estimates, with the purpose of building a reproducible baseline regarding the site selection for in-depth investigations. In the case of Nimatskul (Lake N1), such an investigation led to a down-rating of the hazard. In contrast, the rating for Lake V2, with exactly the same values as for Lake N1, was confirmed in the field.

On the other hand, too conservative ratings had to be avoided. Due to its limited size, the lake in Dashtdara producing the 2002 disaster was rated very susceptible, but only as medium hazardous. Tuning the rating scheme in a way to yield a high or very high hazard for that lake would have led to such a classification of virtually all glacial lakes in the area, obstructing the purpose of the method for site selection. It is likely that superficially invisible factors (structure of the dam, englacial water reservoir) led to the high magnitude of the Dasht 2002 event. One can learn some major lessons by comparing the characteristics of that event to the analysis results:

1. the Dasht lake did not appear more hazardous than many other glacial lakes in the area. This leads to the apparent conclusion that the location of specific outburst events is hard - or even impossible - to predict. The procedure shown in the present paper gives way to a possible strategy of dealing with this problem: identifying potentially dangerous lakes and fostering a broad awarenessraising and preparedness-building connected with feasible technical measures (e.g. simple early warning systems) in possibly affected communities;

2. hazardous glacial lakes may evolve within less than one year. This phenomenon was illustrated not only by the Dasht event, but also by the outburst of the western Zyndan glacier lake in the Tien-Shan (Kyrgyzstan) in 2008 (Narama et al., 2010). This means that careful monitoring of the glacial environment is required in order to keep updated on developing hazards. On the one hand, such monitoring has to be performed by employing remote sensing techniques. On the other hand, the local communities have to be trained and encouraged to keep an eye on relevant environmental changes and developing lakes.

Empirical relationships were used for estimating the travel distances and impact areas of lake outburst floods. This is appropriate at the regional scale as physically-based models would require multiple input parameters not available over such a broad area. Mergili et al. (2011) discuss the challenges and problems connected to physically-based modelling of the motion of lake outburst floods.

However, it should be emphasized that empirical relationships only provide a first estimate of the impact susceptibility which can serve as a baseline for in-depth studies. Specific process chains and interactions regarding the motion of the GLOF are not explicitly considered in the empirical relationships. These include entrainment or deposition of sediment, change between different flow types (flood, hyperconcentrated flow, debris flow), the amplification or attenuation of flood waves by lakes on the flow path (e.g. Lake V1 in Fig. 10c) or backwater effects. In the case of Dasht, such interactions are thought to be responsible for the flow not fitting to the empirical rules derived from sets of other GLOFs (Haeberli, 1983; Huggel, 2004; Huggel et al., 2004a), but instead continuing to the confluence of the Dashtdara with the Shakhdara Valley where lateral spreading was possible. 
The global assumption that an entire lake would drain is realistic when considering small glacial lakes (in Dasht, it was the case), but not for larger lakes with rather stable dams where mass movements may cause an overflow. This problem leads to an overestimation of the lake outburst hazard of large lakes (e.g. Durumkul). Huggel et al. (2004a, b) have related expected outburst volumes to the impact volume - an adoption of this approach would require in-detail investigations for each lake.

An important aspect not explicitly accounted for in the hazard analysis procedure is permafrost, which may significantly influence lake outburst susceptibility and hazard (Haeberli et al., 2010a): in the southwestern Pamir, almost all lakes are located in permafrost areas and a detailed analysis of the condition of the permafrost was out of scope. However, when applying the methodology presented to study regions with lakes both in permafrost and in permafrost-free areas, this aspect has to be included.

\section{Conclusions}

The regional-scale hazard analysis of lake outburst floods, as shown in the present paper for the southwestern Pamir, Tajikistan, has proven to be a valuable tool for a rapid and reproducible identification of potentially hazardous lakes and possible impact areas.

The analysis does not require specialized input data, it largely relies on internationally available medium-resolution satellite imagery and DEMs. This allows an application in remote or poorly developed areas with limited availability of local information. The neglect of such data, however, also limits the scope of the method: it is clearly confined to the identification of areas requiring more detailed investigations, e.g. field studies. The regional-scale analysis has to presume the unknown parameters as utmost unfavourable in order to come up with worst-case assumptions. This avoids missing potentially hazardous lakes and situations during site selection for detailed studies.

The Dasht 2002 event, the most destructive GLOF in the documented history of the southwestern Pamir, originated from a lake rated as very susceptible, but only medium hazardous in the regional-scale analysis. A closer on-site inspection did not reveal a substantial difference to other glacial lakes with such a rating, except for the short lifetime of the lake. This finding underlines the need to detect glacial lakes immediately after their emergence and to take adequate measures.

Also, modelling the travel distance of the Dasht 2002 GLOF showed the difficulties of putting lakes and events into prescribed schemes: it was impossible to reconstruct the reach of the flow by empirical rules based on previous events. This, in conjunction with the thoughts presented above, shows the importance of broad-scale risk mitigation strategies in potentially affected areas, including awareness- raising and preparedness-building within the local population, in combination with regular monitoring of the glacial and periglacial environment.

Acknowledgements. The work presented in this paper was part of the project TajHaz (Remote Geohazards Assessment in Tajikistan) supported by FOCUS Humanitarian Assistance (an affiliate of the Aga Khan Development Network), the Swiss Agency for Development and Cooperation (SDC) and the UK Department for International Development (DFID). Special thanks go to Demian Schneider (University of Zurich) for valuable discussions and contributions and to Anatoli Ischuk (Tajik Institute of Earthquake Engineering and Seismology) for contributions to the calculation of PGA max.

Edited by: J. M. Vilaplana

Reviewed by: W. Haeberli and another anonymous referee

\section{References}

Abdrakhmatov, K., Havenith, H.-B., Delvaux, D., Jongmans, D., and Trefois, P.: Probabilistic PGA and Arias Intensity maps of Kyrgyzstan (Central Asia), J. Seismol., 7, 203-220, 2003.

Allen, S. K., Schneider, D., and Owens, I. F.: First approaches towards modelling glacial hazards in the Mount Cook region of New Zealand's Southern Alps, Nat. Hazards Earth Syst. Sci., 9, 481-499, doi:10.5194/nhess-9-481-2009, 2009.

Babaev, A. M. and Mirzoev, K. M.: Basic principles of seismic zonation of the territory of Tajikistan. Vol.: The questions of the seismic zonation of the territory of Tajikistan, 3-31, Donish Publishing, Dushanbe, 1976.

Babaev, A. M., Lyskov, L. M., Mirzoev, K. M., Achilov, G. S., Lazaridi, L. K., and Rajabov, N. R.: Natural resources of Tajikistan. Seismic sources, 1:500000 scale map, GUGK USSR, 1984.

Breien, H., De Blasio, F. V., Elverhoi, A., and Hoeg, K.: Erosion and morphology of a debris flow caused by a glacial lake outburst flood, Western Norway, Landslides, 5(3), 271-280, 2008.

Carey, M.: Living and dying with glaciers: people's historical vulnerability to avalanches and outburst floods in Peru, Glob. Plan. Change, 47, 122-134, 2005.

Cenderelli, D. A. and Wohl, E. E.: Peak discharge estimates of glacial lake outburst floods and "normal" climatic floods in Mount Everest region, Nepal. Geomorphology, 40, 57-90, 2001.

Clarke, G. K. C.: Glacier outburst floods from 'Hazard Lake', Yukon Territory, and the problem of flood magnitude prediction, J. Glaciol, 28(98), 3-21, 1982.

Corominas, J., Copons, R., Vilaplana, J. M., Altamir, J., and Amigó, J.: Integrated Landslide Susceptibility Analysis and Hazard Assessment in the Principality of Andorra, Nat. Haz., 30, 421-435, 2003.

Costa, J. E.: Floods from Dam Failures, US Geol. Surv. Open File Rep., 85-560, Denver, Colorado, 54 pp., 1985.

Costa, J. E. and Schuster, R. L.: The formation and failure of natural dams, Geol. Soc. Am. Bull., 100, 1054-1068, 1988.

Crosta, G. B., Frattini, P., Fusi, N., and Sosio, R.: Formation, characterization and modelling of the 1987 Val Pola rock-avalanche dam (Italy), Italian J. Eng. Geol. Envir., Special Issue I, 145-150, doi:10.4408/IJEGE.2006-01.S-20, 2006. 
Dussaillant, A., Benito, G., Buytaert, W., Carling, P., Meier, C., and Espinoza, F.: Repeated glacial-lake outburst floods in Patagonia: an increasing hazard?, Nat. Haz., 54(2), 469-489, doi:10.1007/s11069-009-9479-8, 2009.

Evans S. G. and Clague J. J.: Recent climatic change and catastrophic geomorphic processes in mountain environments, Geomorphology, 10(1-4), 107-128, 1994.

Haeberli, W.: Frequency and characteristics of glacier floods in the Swiss Alps, Ann. Glac., 4, 85-90, 1983.

Haeberli, W., Clague, J. J., Huggel, C., and Kääb, A.: Hazards from lakes in high-mountain glacier and permafrost regions: Climate change effects and process interactions. Avances de la Geomorphología en España, 2008-2010, XI Reunión Nacional de Geomorphología, Solsona, 439-446, 2010a.

Haeberli, W., Portocarrero, C., and Evans, S.: Nevado Hualcán, Laguna 513 y Carhuaz 2010 - Observaciones, evaluación y recomendaciones (un corto informe técnico luego de las reuniones y visita de campo en Julio 2010), unpublished report on behalf of the Comunidad Provincial de Carhuaz, 2010b.

Hewitt, K.: Natural dams and outburst floods in the Karakorum Himalaya, in:Hydrological aspects of alpine and high-mountain areas, edited by: Glen J. W., IAHS Publication, 138, 259-269, 1982

Huggel, C.: Assessment of Glacial Hazards based on Remote Sensing and GIS Modeling. Dissertation at the University of Zurich, Schriftenreihe Physische Geographie Glaziologie und Geomorphodynamik, 88 pp., 2004.

Huggel, C., Kääb, A., Haeberli, W., Teysseire, P., and Paul, F.: Remote sensing based assessment of hazards from glacier lake outbursts: a case study in the Swiss Alps, Can. Geotech. J., 39, 316-330, 2002.

Huggel, C., Kääb, A., Haeberli, W., and Krummenacher, B.: Regional-scale GIS-models for assessment of hazards from glacier lake outbursts: evaluation and application in the Swiss Alps, Nat. Hazards Earth Syst. Sci., 3, 647-662, doi:10.5194/nhess-3-647-2003, 2003.

Huggel, C., Haeberli, W., Kääb, A., Bieri, D., and Richardson, S.: Assessment procedures for glacial hazards in the Swiss Alps, Can. Geotech. J., 41(6), 1068-1083, 2004a.

Huggel, C., Kääb, A., and Salzmann, N.: GIS-based modeling of glacial hazards and their interactions using Landsat-TM and IKONOS imagery, Norwegian J. Geogr., 58, 761-773, 2004b.

IPCC: Climate Change 2007: The Physical Science Basis. Contribution of Working Group I to the Fourth Assessment Report of the Intergovernmental Panel on Climate Change, edited by: Solomon, S., Qin, D., Manning, M., Chen, Z., Marquis, M., Averyt, K. B., Tignor, M., and Miller, H. L., Cambridge University Press, Cambridge, United Kingdom and New York, NY, USA, 996 pp., 2007.

Iturrizaga, L.: Historical Glacier-dammed Lakes and Outburst Floods in the Karambar Valley (Hindukush-Karakoram), GeoJournal, 62(3-4), 1-47, 2005a.

Iturrizaga, L.: New observations on present and prehistorical glacier-dammed lakes in the Shimshal valley (Karakoram Mountains), J. Asian Earth Sci., 25(4), 545-555, 2005b.

Jarvis, A., Reuter, H. I., Nelson, A., and Guevara, E.: Hole-filled seamless SRTM data V4. International Centre for Tropical Agriculture (CIAT), available at: http://srtm.csi.cgiar.org, 2008.

Kääb, A., Huggel, C., Fischer, L., Guex, S., Paul, F., Roer, I., Salz- mann, N., Schlaefli, S., Schmutz, K., Schneider, D., Strozzi, T., and Weidmann, Y.: Remote sensing of glacier- and permafrostrelated hazards in high mountains: an overview, Nat. Hazards Earth Syst. Sci., 5, 527-554, doi:10.5194/nhess-5-527-2005, 2005

Kargel, J. S., Leonard, G., Crippen, R. E., Delaney, K. B., Evans, S. G., and Schneider, J. F.: Satellite Monitoring of Pakistan's Rockslide-Dammed Lake Gojal, EOS, 91(43), 394-395, doi:10.1029/2010EO430002, 2010.

Kassam, K. A.: Viewing Change Through the Prism of Indigenous Human Ecology: Findings from the Afghan and Tajik Pamir, Hum. Ecol., 37, 677-690, 2009.

Mergili, M., Schneider, D., Worni, R., and Schneider, J. F.: Glacial Lake Outburst Floods (GLOFs): challenges in prediction and modelling. Accepted for the Proceedings of the 5th International Conference on Debris-Flow Hazards Mitigation: Mechanics, Prediction and Assessment, Padova, 14-17 June, 2011.

Murphy, W., Petley, D. N., Bommer, J., and Mankelow, J. M.: Uncertainty in ground motion estimates for the evaluation of slope stability during earthquakes, Q. J. Eng. Geol. Hydroge., 35, 7178, 2002.

Narama, C., Duishonakunov, M., Kääb, A., Daiyrov, M., and Abdrakhmatov, K.: The 24 July 2008 outburst flood at the western Zyndan glacier lake and recent regional changes in glacier lakes of the Teskey Ala-Too range, Tien Shan, Kyrgyzstan, Nat. Hazards Earth Syst. Sci., 10, 647-659, doi:10.5194/nhess-10-6472010, 2010.

O'Connor, J. E., Hardison, J. H., and Costa, J. E.: Debris flows from failures of Neoglacial-Age moraine dams in the Three Sisters and Mount Jefferson wilderness areas, Oregon, US Geological Survey Professional Paper, 1606, 93 pp., 2001.

Quincey, D. J., Richardson, S. D., Luckman, A., Lucas, R. M., Reynolds, J. M., Hambrey, M. J., and Glasser, N. F.: Early recognition of glacial lake hazards in the Himalaya using remote sensing datasets, Glob. Plan. Change, 56(1-2), 137-152, 2007.

Reynolds, J.: Development of glacial hazard and risk minimisation protocols in rural environments. Guidelines for the management of glacial hazards and risks. Reynolds Geo-Sciences Independent Geological Consultants, Report No: R7816, Mold, UK, 2003.

Richardson, S. D. and Reynolds, J. M.: An overview of glacial hazards in the Himalayas, Quatern. Int., 65/66, 31-47, 2000.

Rickenmann, D.: Empirical Relationships for Debris Flows, Nat Haz., 19, 47-77, 1999.

Schneider, J. F., Gmeindl, M., and Traxler, K.: Risk Assessment of Remote Geohazards in Central and Southern Pamir/GBAO, Tajikistan. Report to the Ministry of Emergency, Tajikistan and the Swiss Agency for Development and Cooperation (SDC), 2004.

Tinti, S., Maramai, A., and Cerutti, A. V.: The Miage Glacier in the Valley of Aosta (Western Alps, Italy) and the extraordinary detachment which occurred on 9 August 1996, Phys. Chem. Earth (A), 24(2), 157-161, 1999.

Vilímek, V., Zapata, M. L., Klimes, J., Patzelt, Z., and Santillán N.: Influence of glacial retreat on natural hazards of the Palcacocha Lake area, Peru, Landslides, 2(2), 107-115, 2005.

Walder J. S. and Costa J. E.: Outburst floods from glacierdammed lakes: the effect of mode of lake drainage on flood magnitude, Earth Surf. Proc. Landforms, 21, 701-723, 1996.

Walder, J. S. and O'Connor, J. E.: Methods for Predicting Peak Dis- 
charge of Floods Caused by Failure of Natural and Constructed Earth Dams, Water Resour. Res., 33(10), 2337-2348, 1997.

Wang, X., Nie, G., and Wang, D.: Relationships between ground motion parameters and landslides induced by Wenchuan earthquake, Earthquake Sci., 23(3), 233-242, 2010.
Watanabe, T. and Rothacher, D.: The 1994 Lugge Tsho glacial lake outburst flood, Bhutan Himalaya, Mt. Res. Dev., 16, 77-81, 1996. 